\title{
EL TERRORISMO GLOBAL. INICIO, DESAFÍOS Y MEDIOS POLÍTICO-JURÍDICOS DE ENFRENTAMIENTO
}

\author{
Pablo César Revilla MonTOYA*
}

RESUMEN: El terrorismo global es un término novedoso que nace con el megaterrorismo visible desde los atentados del 11 de septiembre del 2001, el cual se deriva de la privatización del terrorismo internacional. ¿Cómo se inició el terrorismo global?, ¿cuáles son sus desafíos? y ¿cuáles sus medios políticos y jurídicos de enfrentamiento? son las preguntas que se intenta resolver en este artículo.

ABSTRACT: Global terrorism is a novel term that emerged with the megaterrorism that followed 9/11, derived from the privatization of international terrorism. How was the global terrorism started? Which are its challenges? And, which are its political and legal means of fight? These are the questions the author intends to find out thoroughout this article.

RÉSUMÉ: La notion de terrorisme mondial c'est un terme nouveau qui apparût lors du megaterrorisme visible depuis les attentats de 11 de séptembre 2001 et il dérive de la privatisation del terrorisme international. Comment s'est inicié le terrorisme mondial ? Quels sont ses défis? Et quels sont les moyens politiques et juridiques nécessaires pour l'affronter? Celles-ci sont les questions que l'auteur se propose d'éclairer dans cet article.

* Miembro investigador del Taller de Derecho Internacional (Tadi), Facultad de Derecho y Ciencia Política de la Universidad Nacional Mayor de San Marcos de Lima (2002-2004). www.unmsm.edu.pe/derecho/tadi. Un agradecimiento especial al señor Ricardo Morote Canales, ministro consejero del servicio diplomático del Perú, por sus importantes críticas y recomendaciones. 
SUMARIO: I. Introducción. II. Consecuencias del 11 de septiembre. El terrorismo global, la doctrina Bush y la guerra contra el terrorismo. III. ¿La globalización del terrorismo, terrorismo en la era de la globalización o terrorismo global? IV. Afrontar al terrorismo global, tarea de la comunidad internacional. V. Conclusiones.

\section{INTRODUCCIÓN}

El aciago 11 de septiembre del 2001 (11-S) trajo consigo, además de la indignación mundial y un nuevo orden político-jurídico internacional, la aparición de un nuevo fenómeno: el terrorismo global.

Las nuevas dimensiones con que se ha presentado el terrorismo global son la novedad. Por ello, manejaremos en este trabajo la definición más amplia de terrorismo; es decir, como un mecanismo político que usa la violencia para llegar a ciertos fines, además podemos observar que existe un elemento que identifica visiblemente dicho crimen: el objetivo de crear una atmósfera de terror.

En este artículo, entonces, trataremos de describir cómo se presenta el terrorismo global tras los atentados del 11-S. Además explicaremos el fenómeno del terrorismo global diferenciándolo de la globalización del terrorismo; por último, detallaremos la manera cómo la comunidad internacional afronta al terrorismo global.

\section{CONSECUENCIAS DEL 11 DE SEPTIEMBRE. EL TERRORISMO GLOBAL, LA DOCTRINA BUSH Y LA GUERRA CONTRA EL TERRORISMO}

En este capítulo explicaremos mediante una visión evolutiva al nuevo fenómeno que ha desestabilizado el orden mundial: el terrorismo global. Además explicaremos algunas de sus características más relevantes incluyendo finalmente una definición personal.

\section{Evolución del terrorismo}

Si bien es cierto que el fenómeno terrorista es mas bien un fenómeno moderno y que sus antecedentes más relevantes se encuentran en la revolución francesa con el "Régimen del terror", así como con hechos vincu- 
lados a la lucha revolucionaria (en la Rusia zarista de los Romanov) y en el nacionalismo imperialista de la restauración Medji en contra del shogunado de los Tokugawa en Japón, ${ }^{1}$ los hechos terroristas más resaltantes de las últimas décadas serán parte de este punto.

Podemos afirmar que el terrorismo ha pasado por un proceso histórico. En forma general, en el pasado más reciente, sesentas y setentas, el terrorismo internacional tenía como principal objetivo la liquidación de sus víctimas en medio de una gran audiencia. Ejemplo, "Septiembre negro" en las olimpiadas de Munich. Los principales eran sobre todo, grupos denominados revolucionarios que tenían una estrategia de toma de poder (terrorismo político).

Adicionalmente, en las dos últimas décadas de la Guerra Fría, se hace presente el terrorismo internacional, es decir cuando los Estados empezaron a financiar o patrocinar actos terroristas para desestabilizar a otros Estados.

En los ochenta se comenzó a utilizar las bombas (coches bomba, paquetes bomba, etcétera) que mataban tan rápido que no dejaban tiempo para una intervención. Se añadieron los motivos religiosos como objetivos y se añade como base social a los militantes islámicos.

En los noventa, los objetivos políticos se combinaron con objetivos económicos. Se comienzan a atacar símbolos del poder económico; así, las Torres Gemelas de Nueva York sufren su primer ataque en 1993. A los grupos islámicos, revolucionarios, se añaden los grupos del crimen organizado (como el narcoterrorismo).

También en los noventa se comienza a hablar del uso de armas de destrucción masiva (como armas químicas, biológicas y bacteriológicas) para fines terroristas. En 1990, Los Tigres de la Liberación de Tamil Eelam (LTTE) en el norte de Sri Lanka, atacaron a las Fuerzas Armadas de Sri Lanka (SLAF) a base de gas clorina, dañando a más de 60 militares. En 1995 el grupo Verdad Suprema (Aum Shinrikyo) atacó el metro de Tokyo con gas sarin. ${ }^{2}$

El caso del envío de ántrax por correo postal, inmediatamente después de los atentados del 11-S, perpetrado por el grupo Al-Qaeda de

1 Olloqui, José Juan, "Introducción. Reflexiones en torno al terrorismo", en Olloqui, José Juan (coord.), Problemas jurídicos y políticos del terrorismo, México, UNAM, Instituto de Investigaciones Jurídicas, 2003, p.13.

2 Parachini, John, "Putting WMD Terrorism into Perspectiva", The Washington Quarterly, otoño de 2003, pp. 39 y 40. 
Osama Bin Laden, representa el surgimiento del bioterrorismo. ${ }^{3}$ Sin embargo, el sólo hecho de pensar que los terroristas podrían tener acceso a tecnología nuclear crea un temor generalizado.

Después de los sucesos del fatídico 11-S, dichos actos fueron calificaron como actos terroristas por el Consejo de Seguridad en su Resolución 1368 (2001); empero, el presidente de Estados Unidos de América los declaró actos de guerra, y siguió insistiendo en ello. Terrorismo y guerra se mezclarían ${ }^{4}$ según la percepción estadounidense.

Ciertamente, no estamos asistiendo en estos momentos a una revolución comparable a las que se produjeron en el pasado. ${ }^{5}$ El terrorismo mundial no representa a toda la miseria del mundo. Pero este nuevo terrorismo ha desestabilizado el orden mundial, por lo que nos hace repensarlo como fenómeno global.

\section{El terrorismo global. Características}

Identificar cuáles son las características que hacen peculiar al llamado terrorismo global no es muy difícil, sólo basta dar un vistazo a los atentados del 11-S y sus consecuencias.

El 11-S nos dejó no sólo la demostración de hasta dónde puede llegar la barbarie terrorista, sino que además nos dejó la aparición de un fenómeno que no es nuevo, pero que a partir de entonces se pinta con un matiz especial: el terrorismo global.

El terrorismo global es hoy en día la amenaza más importante y real para los principios en los que se basa el sistema mundial actual. En ese sentido, el 11-S nos ha dejado varias lecciones, como que ningún argumento político, moral o histórico puede justificar el terrorismo, que por su propia naturaleza, se descalifica a sí mismo. ${ }^{6}$

El aforismo a menudo repetido de que el terrorista es un luchador por la libertad, indica la dificultad para definir legalmente el término te-

3 Hernández Campos, Augusto, "El derecho internacional y la guerra biológica", Revista del Foro, año MMII, núm. 2, 2002, p. 257.

4 Haro Tegglen, Eduardo, La guerra de Nueva York, Madrid, Ediciones Santillana, 2001, p. 24.

5 Augé, Marc, Diario de Guerra. El mundo después del 11 de septiembre, Barcelona, Gedisa, 2002, p. 30.

6 Perpiñá Robert, Fernando, "El mundo tras el 11 de septiembre", en varios autores, Problemas jurídicos y políticos del terrorismo, México, UNAM, Instituto de Investigaciones Jurídicas, 2003, p. 347. 
rrorismo internacional. ${ }^{7}$ Sin embargo, existe la necesidad de una definición legal y precisa del término 'terrorismo internacional', que implique una amenaza a la preservación de la paz y a la seguridad internacionales.

En todo caso, el terrorismo visto de una manera amplia es un método político que utiliza la violencia para llegar a ciertos fines, de ahí que el terrorismo pueda ser utilizado tanto por el Estado como por grupos asimétricos (como Al Qaeda).

Además, podemos observar que existe un elemento que identifica visiblemente a ese crimen internacional: el objetivo de crear una atmósfera de terror. ${ }^{8}$

Según Montealegre Klenner, ${ }^{9}$ las prácticas terroristas no respetan las normas humanitarias de los conflictos, sino que, al contrario, lo característico de ellas es violarlas, por ello el derecho internacional las cataloga como crímenes contra la humanidad. Por eso los terroristas no tendrían el estatus de beligerante.

De ahí que, el terrorismo en sí no debe ser confundido con la guerra de guerrillas. La guerrilla se conforma con las normas de los conflictos armados, es en realidad una fuerza armada irregular ${ }^{10}$ que puede o no utilizar prácticas terroristas, pero que para ser considerada como beligerante debe cumplir con las reglas del derecho internacional humanitario.

Visiblemente los grupos terroristas no poseen estas características de beligerancia, son más bien transgresores de los principios y costumbres de convivencia pacífica aceptadas por los Estados, violando sistemática e indiscriminadamente los derechos humanos de las personas y las normas mínimas de respeto mutuos reconocidos a nivel nacional y mundial. ${ }^{11}$

Manuel Castells ${ }^{12}$ afirma hábilmente que si la guerra es la continuación de la política por otros medios, según la fórmula consagrada de

7 Friedlander, Robert A., “Terrorism”, en Bernardt, R. (ed.), Encyclopedia of Public International Law, vol. IV, 2000, p. 846.

8 Becerra Ramírez, Manuel, "El 11 de septiembre y el derecho internacional", en varios autores, Globalidad y conflicto. Estados Unidos y la crisis de septiembre, México, UNAM, Instituto de Investigaciones Jurídicas, 2002, p. 259.

9 Ramella, Pablo A., Crímenes contra la humanidad, Buenos Aires, De Palma, 1986, p. 110.

10 Gómez-Robledo Verduzco, Alonso, Temas selectos de derecho internacional, México, UNAM, Instituto de Investigaciones Jurídicas, 2003, p. 640.

11 Ramaccioti Rubio, Beatriz, "El terrorismo como crimen internacional", Agenda Internacional, Lima, año 3, núm. 92, enero-junio de 1996, p. 162.

12 Castells, Manuel, "Combatir el terrorismo", Observatorio Social, Copyright La Vanguardia Ediciones S. L.-Iniciativas Digital Media S. L., 1o. de mayo de 2004 (documento en línea). http:// www.sepv.org/observatorio/social/terrorismo_castells.pdf (consulta: 29 de mayo del 2004). 
Clausewitz, el terrorismo es la continuación de la guerra por otros medios. Es la forma predominante de guerra en nuestro mundo.

Sin embargo, lo cierto es que el terrorismo es considerado como crimen de lesa humanidad en tiempos de paz y como crimen de guerra en tiempos de guerra.

Ahora bien, la transnacionalización del terrorismo y su patrocinio estatal para incidir sobre la estabilidad de otros países o sobre el modo en que se ordena regiones enteras del planeta, es lo que se conoce, en términos generales, como terrorismo internacional. ${ }^{13}$ Es decir que, cuando un Estado financia grupos asimétricos para que éstos cometan acciones terroristas en otro Estado, se configuraría el terrorismo internacional.

Pero ¿por qué si el terrorismo no es un fenómeno nuevo ahora se le da tanta importancia? ¿Porque recién abrieron los ojos las grandes potencias o porque alguien así lo dispuso? La respuesta es no.

Si nos remontamos unos años atrás, la combinación de entidades estatales y actores no estatales, unido a los avances tecnológicos de las comunicaciones, permitió que Al Qaeda adquiriera el alcance mundial suficiente, como para configurar un auténtico terrorismo global.

La mayor novedad registrada en el terrorismo internacional, que combina precisamente los efectos de la globalización y la influencia del hecho religioso en su versión integrista, radica en la formación y el desarrollo de Al Qaeda, que es una sofisticada red terrorista que subsiste sin depender de patrocinadores estatales. ${ }^{14}$

Esta característica del terrorismo internacional de nuestros días de no depender de patrocinio estatal alguno lo identifica como 'terrorismo internacional privatizado'. ${ }^{15}$

"Pues bien, ese terrorismo internacional privatizado se ha tornado en terrorismo global y tiene entre sus indicadores más asombrosos al megaterrorismo. Tal y como se manifestó aquel 11 de septiembre del 2001"16 o el 11 de marzo del 2004.

Lo que hace distinto esta nueva clase de terrorismo, el global, es su alcance mundial que lo convierte en un megaterrorismo capaz de desestabilizar un régimen político en un solo día. En España, los atentados del

13 Reinares, Fernando, Terrorismo global, Madrid, Taurus, 2003, p. 30.

14 Ibidem, p. 49.

15 Término introducido por Reinares. Idem.

16 Ibidem, p. 50. 
11 de marzo del 2004 dieron lugar a la pérdida de las elecciones del régimen de Aznar y el Partido Popular.

Los atentados del 11-S no sólo significaron una amenaza sin precedentes a la seguridad mundial, sino que cambiaron de manera apocalíptica el orden mundial imperante.

Por ello, el nuevo "nuevo orden mundial" implica dejar a un lado el desarrollo económico, social, cultural o el cuidado medio ambiental, para darle más interés a la seguridad, despreciando los derechos humanos, el derecho internacional humanitario y las reglas imperativas del derecho internacional general.

Este nuevo terrorismo global encarna una violencia sin límites, practicada por fundamentalistas islámicos, que amenaza el mantenimiento de la seguridad mundial, el pacífico entendimiento entre civilizaciones y la viabilidad misma de los regímenes democráticos. ${ }^{17}$

Finalmente, podemos afirmar que el terrorismo global, por su alcance mundial, es aquel que pone en peligro la paz y seguridad internacionales. Sin embargo, su enfrentamiento debe basarse en el cumplimiento fiel de las normas del ius cogens internacional.

Ahora bien, esta definición es meramente metodológica, ya que en realidad todo aquel terrorismo que viole las normas ius cogens debe ser condenado por la comunidad internacional.

De ahí que tanto el terrorismo de Estado como el terrorismo global "son, hoy por hoy, los principales retos o amenazas a la seguridad mundial". ${ }^{18}$

\section{La doctrina Bush (doctrina de las guerras preventivas)}

La doctrina preventiva de Bush no es un diseño novedoso que nace como consecuencia de los ataques del 11 de septiembre, en realidad esta doctrina ha sido diseñada por un grupo de la élite neoconservadora estadounidense en sendos documentos que son publicados en la página $\mathrm{Web}$ del Project for the New American Century. ${ }^{19}$ En este punto vamos a ex-

17 Ibidem, p. 10.

18 Piñeyro, José Luis, "La seguridad mundial luego del macroterrorismo del 11 de septiembre de 2001: repercusiones y reflexiones", en varios autores, Globalidad y conflicto. Estados Unidos y la crisis de septiembre, México, UNAM, Instituto de Investigaciones Jurídicas, 2002, p.145.

19 Http://www.newamericancentury.org/. 
plicar la doctrina preventiva de Bush en cuanto a su evolución, configuración y síntesis.

\section{A. Evolución de la doctrina preventiva de Bush}

La doctrina de las guerras preventivas del presidente Bush tiene una evolución cronológica que empieza con el fin de la Guerra Fría. El debate sobre la naturaleza y el futuro de la única superpotencia mundial se hizo patente en este periodo. Así podemos citar a Paul Wolfowitz ${ }^{20}$ como el exponente de la doctrina del dominio mundial, a nuestro entender.

En 1992 se filtró un documento del Pentágono, suscrito por Wolfowitz, ${ }^{21}$ sobre la estrategia estadounidense en la posguerra fría. Allí se afirma que Estados Unidos de América debe utilizar todo su poderío militar para prevenir la proliferación de armas de destrucción masiva (ADM) actuando incluso de manera unilateral si las circunstancias así lo requieren.

En 1997 hace su aparición The Project for the New American Century (PNAC), organización fundada por neoconservadores que no estaban de acuerdo con la política exterior del presidente Bill Clinton y que afirmaban que Estados Unidos de América debería tener un liderazgo militar mundial. ${ }^{22}$

Para septiembre del 2000 el PNAC publica su informe Rebuilding America's Defenses: Strategy, Forces and Resources for a New Century en donde se busca una nueva estrategia militar estadounidense bajo los principios de neutralizar la proliferación de ADM, mantener una cantidad considerable de fuerzas que se puedan desplegar en diferentes escenarios a la vez, transformar la fuerzas armadas con nueva tecnología, etcétera. $^{23}$

Sin embargo, en el capítulo $\mathrm{V}$ del mencionado informe se advierte que el proceso de transformación de las fuerzas armadas estadouniden-

20 Vicesecretario de defensa en la administración Bush, de padre e hijo.

21 Un extracto del proyecto lo podemos ver en la siguiente página Web: http://www.pbs.org/ wghh/pages/frontline/shows/iraq/etc/wolf.html.

22 Véase la Declaración de Principios del PNAC en la página Web:http://www.newamerica ncentury.org/statementofprinciples.htm

23 The Project for the New American Century, Rebuilding America's Defenses: Strategy, Forces and Resources for a New Century, Washington, D. C., PNAC, 2000, p. 6. Publicado también en la Internet en la siguiente página Web: http://www.newamericancentury.org/RebuildingAmericas Defenses.pdf. 
ses, a pesar de los cambios revolucionarios, será prolongado, falto de algún suceso catastrófico, como un nuevo Pearl Harbour. ${ }^{24}$

A principios del 2001, con el presidente George W. Bush en el poder, los únicos signos visibles de su adhesión a la doctrina preventiva fueron la inclusión en su equipo de gobierno a los que firmaron la Declaración de Principios de la PNAC, es decir, Dick Cheney, Donald Rumsfeld y Paul Wolfowitz.

\section{B. La nueva estrategia de seguridad nacional de Estados Unidos de América}

Tras los atentados del 11-S la respuesta estadounidense no se hizo esperar, George W. Bush, el 20 de septiembre del 2001, invocó su famosa doctrina preventiva ante el Congreso estadounidense y dirigida también al mundo entero: "Quitaremos el financiamiento a los terroristas, los volveremos uno contra el otro, los haremos moverse de un lugar a otro hasta que no tengan refugio ni descanso. Y perseguiremos a todas las naciones que proporcionen ayuda o refugio al terrorismo. Todas las naciones en todas las regiones deben tomar ahora una decisión: o están con nosotros o están con los terroristas". ${ }^{25}$

El presidente Bush, en su discurso ante la Asamblea General de las Naciones Unidas, el 12 de septiembre del 2002, aprovechando el aniversario del atentado terrorista contra las Torres Gemelas de Nueva York, proclamó la legitimidad de un ataque preventivo contra cualquier amenaza terrorista a Estados Unidos de América y anunció que empezaría por Irak, con las "resoluciones necesarias" del Consejo de Seguridad o sin ellas. Sin embargo, Bush ya había anunciado su doctrina de la guerra preventiva en la Academia Militar de West Point ${ }^{26}$ el 1 de junio pasado. ${ }^{27}$

Muchas voces se hicieron escuchar tras estas declaraciones: tanto el vicepresidente como el secretario de defensa, además de otras personali-

24 Ibidem, p. 51.

25 Distribuido por la Oficina de Programas de Información Internacional del Departamento de Estado de Estados Unidos de América. Sitio en la Web, http://usinfo.state.gov/espanol/.

26 Se puede leer el discurso en la siguiente dirección electrónica:http://www.whitehouse.gov/news/ releases/2002/06/20020601-3.html.

27 Ojeda, Jaime, "La doctrina Bush. Guerra preventiva, dominación mundial", Política Exterior, vol. XVI, núm. 90, 2002, p. 7. 
dades belicistas como el subsecretario de defensa Paul Wolfowitz, ${ }^{28}$ estuvieron reiterando dicha tesis por todo el país, haciendo caso omiso e incluso desairando al secretario de Estado, Colin Powell. Sin embargo, destacadas personalidades del gobierno de George Bush padre, especialmente Brent Scowcroft y James Baker, pero también Henry Kissinger y Zbigniew Brzezinski, tuvieron que acudir a publicar cartas en la prensa aconsejando mayor prudencia, y a no aventurarse a una acción militar sin el apoyo de la ONU y la coalición de sus aliados, como hizo el primer presidente Bush con tanta habilidad como éxito en 1991. ${ }^{29}$

$\mathrm{Y}$ es que en los albores del siglo XXI existían dos realidades en ojos de Bush la posibilidad de otro ataque terrorista similar al del 11-S y la proliferación de $\mathrm{ADM}$, que en manos de terroristas conllevaría a que Estados Unidos de América sufra un ataque en el que mueran cientos de miles de personas. Como se pregunta Bob Woodward ${ }^{30}$ ¿qué ocurriría en un ataque nuclear hacia Estados Unidos de América? un país libre podría convertirse en un Estado policial, se responde.

El 17 de septiembre del 2002, la administración Bush, publicó su primer informe sobre la Estrategia Nacional de Seguridad (ENS) ${ }^{31}$ que por legislación debe presentar al congreso, allí define formalmente la doctrina preventiva que venía anunciando desde junio, extendiendo el concepto de prevención contra un peligro inminente al de atacar primero para impedir que se materialice una amenaza en el futuro. ${ }^{32}$

Según la ESN, los enemigos de Estados Unidos de América han declarado abiertamente su intención de adquirir armas de destrucción masiva $(\mathrm{ADM})$ y por ello Estados Unidos de América actuará contra dichas amenazas antes que éstas se configuren por completo. Por otro lado, La ESN plantea una fórmula mixta que contempla, de una parte, el derecho a la autodefensa y, de otra, el reforzamiento de las medidas de contraproliferación de ADM como el despliegue de un sistema nacional de defensa

28 Principal arquitecto de la doctrina preventiva, famoso por haber redactado documentos — tanto en 1992, como de 1998 en adelante - sobre la seguridad estadounidense, sobre aumento de gastos militares y la peregrinación del unilateralismo. Miembro del Project for the New American Century (Proyecto para el Nuevo Siglo Estadounidense), podemos encontrar sus aportes a dicha doctrina en la página Web: http://www.newamericancentury.org/.

29 Ibidem, p. 8.

30 Woodward, Bob, Bush en guerra, Barcelona, Ediciones Península, 2002, p. 380.

31 Con la publicación de este documento se dio un espaldarazo a los neoconservadores que afirman la unilateralidad estadounidense. Este documento se puede encontrar en la página Web: http://www.whitehouse.gov/nsc/nss.pdf.

32 Ibidem, p. 9. 
antimisiles, además de la mejora de la inteligencia operativa y la transformación de las fuerzas armadas. ${ }^{33}$

La doctrina preventiva del presidente Bush, para algunos autores, supone un cambio radical en relación con la posibilidad de que Estados Unidos de América pueda utilizar su armamento nuclear contra otro Estado que amenace su seguridad, echando por la borda la doctrina de la disuasión. La razón principal de dicho cambio, al menos la oficial, es que frente a actores no estatales, como los grupos terroristas, la disuasión tiene un papel limitado. ${ }^{34}$

\section{La guerra contra el terrorismo}

Luego del los atentados del 11-S del 2001, Estados Unidos de América inició su "guerra contra el terrorismo" atacando a Afganistán el 7 de octubre, con apoyo del Consejo de Seguridad. Luego Bush señaló como "el eje del mal"35 a Irak, Irán y Corea del Norte, por poseer armas de destrucción masiva, por su apoyo al terrorismo y por poseer armas nucleares respectivamente.

Sin embargo, la mal llamada 36 "guerra contra el terrorismo", consecuencia notable de la doctrina preventiva del presidente George W. Bush, no ha hecho más que "reflejar una visión extremista de la política exterior de la primera superpotencia". 37

En otras palabras, la existencia de la doctrina de las guerras preventivas de Bush se explicaría con la llamada "guerra contra el terrorismo", aunque no sería la única explicación como lo demuestran documentos publicados por Paul Wolfowitz.

33 Garrido Rebolledo, Vicente, "Proliferación y la doctrina Bush", Politica Exterior, vol. XVII, núm. 95, 2003, p. 67.

34 Idem.

35 Término introducido por Michael Geerson, director del grupo que escribe los discursos presidenciales, utilizando el lenguaje teológico que Bush empleaba desde el 11 de septiembre de 2001. Laurent, Eric, El mundo secreto de Bush, Buenos Aires, Ediciones B, 2003, p. 85.

36 Hablar de guerra en el derecho internacional implica la "confrontación armada entre dos o más Estados, llevada a cabo por las fuerzas armadas respectivas" (Verri, Pietro, Diccionario de derecho internacional de los conflictos armados, Bogotá, CICR, 1998, p. 45), es decir, no puede llamarse guerra a un conflicto asimétrico, como lo es la lucha antiterrorista.

37 Brzezinski, Zbigniew, "La seguridad de EE. UU. en un mundo unipolar", Política Exterior, vol. XVIII, núm. 97, 2004, p. 59. 


\section{III. ¿LA GLOBALIZACIÓN DEL TERRORISMO, TERRORISMO \\ EN LA ERA DE LA GLOBALIZACIÓN \\ O TERRORISMO GLOBAL?}

En este capítulo diferenciaremos los términos "globalización del terrorismo" del "terrorismo global". Estos términos parecen sinónimos, sin embargo tienen ciertos matices que lo hacen similares pero no idénticos.

\section{El terrorismo en la era de la globalización}

El concepto de globalización del terrorismo indica cómo el terrorismo aprovecha la globalización para llegar o dirigirse a un público, para cumplir con sus objetivos.

Aquí no vamos a entrar al debate sobre la viabilidad o no de la globalización, sólo vamos a describir hechos específicos que han sido aprovechados por los grupos terroristas.

Así, las tendencias a la globalización comprenden procesos contradictorios de homogenización y heterogeneización, de inclusión y exclusión, de integración y marginación. El mundo no se ve más interdependiente, homogéneo, igualitario y unificado, por el contrario se polariza aceleradamente.

Las políticas globales van en detrimento de los países pobres y a favor de los centros desarrollados. ${ }^{38}$

"El desorden de la globalización con sus lacerantes incrementos de las diferencias, los incontenibles flujos migratorios huyendo de la miseria o de la tiranía, la imprevisibilidad del casino financiero internacional o los crecientes odios interculturales, reclama un esfuerzo de construcción del nuevo orden internacional del siglo XXI". 39

La globalización se ha convertido en un caldo de cultivo del terrorismo global, dado que "una proporción sustancial de la población mundial está ampliamente excluida de los beneficios de la globalización". ${ }^{40}$

38 Kaplan, Marcos, "El sistema internacional: límites, paradojas y posibilidades", en varios autores, Globalidad y conflicto. Estados Unidos y la crisis de septiembre, México, UNAM, Instituto de Investigaciones Jurídicas, 2002, p. 179.

39 Gonzáles, Felipe, "Globalización del terror", en varios autores, El mundo después del 11 de septiembre de 2001, Barcelona, Ediciones Península, 2002, p. 50.

40 Held, David y McGrew, Anthony, Globalización-antiglobalización. Sobre la reconstrucción del orden mundial, Barcelona, Paidós, 2003, p. 13. 
La extensión geográfica del terrorismo internacional obedece a la difusión e intensificación de ciertos factores, así como los más recientes avances tecnológicos aplicados a la comunicación y al flujo de capitales. ${ }^{41}$

Obedece en suma, al proceso de interconexión e interdependencia que denominamos globalización. Pero la globalización del terrorismo no se refiere únicamente al hecho de que semejante fenómeno se manifieste a lo largo y ancho del planeta. Como consecuencia de la llamada sociedad de la información, esa violencia transnacionalizada tiende a adoptar una estructura horizontal en redes, con un contingente de activistas más bien difuso. 42

\section{Factores de la globalización que potencia al terrorismo} internacional

Existen muchos factores que pueden potenciar al terrorismo global, pero vamos a describir sólo los más resaltantes que se derivan de la era de la globalización.

\section{A. La debilidad del Estado ante el aumento del comercio mundial}

La expansión de la democracia no ha ido de la mano con la fortaleza de sus instituciones, especialmente en América Latina. La crisis del Poder Judicial a nivel regional, como nos recuerda un reciente informe del PNUD, ${ }^{43}$ lo vuelve ineficiente para combatir el tráfico ilegal en las zonas fronterizas, por ejemplo.

Moisés Naim, director de la prestigiosa revista estadounidense $F_{O}$ reign Policy, en un reciente artículo, "Las cinco guerras de la globalización", nos recuerda el auge del tráfico de drogas, armas, propiedad intelectual, gente y dinero ilegal en el mundo. Justamente en la actualidad, el terrorismo internacional se alimenta cada vez más de dicho tráfico y menos de contribuciones personales.

41 Reinares, Fernando, op. cit., nota 13, p. 46.

42 Idem.

43 Programa de las Naciones Unidas para el Desarrollo (PNUD), La democracia en América Latina.Hacia una democracia de ciudadanas y ciudadanos, Nueva York, PNUD, 2004. 


\section{B. El desarrollo de Internet}

Lo que nos parecía una herramienta para el desarrollo, también sirve para potenciar el terrorismo. Paradójicamente, un instrumento para descentralizar las redes de comunicación por computadoras en Estados Unidos de América ante un eventual conflicto con la URSS en la década de los setenta, se ha convertido en una de las herramientas preferidas por el terrorismo internacional.

Hoy cualquier organización terrorista que se respete a sí misma, tiene una página en Internet. Entre las ventajas que ofrece el Internet para los grupos terroristas está su fácil acceso, pequeña o ninguna regulación $\mathrm{u}$ otra forma de control de gobierno, puede llegar a grandes audiencias, se puede comunicar anónimamente y ocultar identidades, su elaboración y mantenimiento es barato.

Internet se convierte así, para el nuevo terrorismo internacional, en el medio que facilita tareas fundamentales como las de proselitismo y reclutamiento, almacenamiento y tratamiento de datos, o incluso la gestión de recursos financieros disponibles. ${ }^{44}$

\section{AFRONTAR AL TERRORISMO GLOBAL, TAREA DE LA COMUNIDAD INTERNACIONAL}

No es fácil hacerle frente al terrorismo global, por ello es tarea de la comunidad internacional en su conjunto enfrentar este flagelo de una manera concertada tanto política como jurídicamente.

\section{Guerra contra el terrorismo global: excusa para las guerras preventivas}

Es sabido que una de las excusas para invadir Irak fue su posible alojamiento de grupos terroristas, así como vínculos entre Saddam Hussein y Al Qaeda. En este punto analizaremos si en verdad el terrorismo global está siendo tomado como excusa para la intervención y la violación de soberanía territorial, así como de las guerras preventivas. 


\section{A. Los ataques del 11 de septiembre. Justificación} de las guerras asimétricas

Luego de los execrables atentados del 11-S, Estados Unidos de América dio un giro a su política exterior redondeando su posicionamiento estratégico como superpotencia mundial.

A pesar de no ser un ejército convencional el que realizó dichos atentados, la bestial dimensión ${ }^{45}$ demostraba la vulnerabilidad del sistema de seguridad estadounidense.

La "guerra contra el terrorismo" se configuró en palabras del presidente George W. Bush en dos ideas claves: los ataques terroristas como actos de guerra, que otorgaban a Estados Unidos de América el legítimo derecho de la autodefensa, y; catalogar como enemigos a los países que supuestamente apoyan a las organizaciones terroristas. ${ }^{46}$

La primera idea rompe la tradicional idea de guerra, como conflicto bélico entre Estados, y define "un nuevo tipo de conflicto asimétrico entre la potencia más poderosa a nivel mundial y un enemigo casi virtual, con una estructura transnacional descentralizada, convenientemente insertada dentro del amplio horizonte de la globalización, y con un modus operandi cualitativamente distinto que, en lugar de atacar frontalmente a su enemigo, buscaba golpearlo y desestabilizarlo aprovechando sus puntos débiles". ${ }^{47}$

La guerra en Afganistán sería entonces la consecuencia lógica del 11-S, castigando así a un país que "apoyaba el terrorismo". ${ }^{48}$

Si la OTAN invocó la cláusula de defensa común por primera vez en su historia, el Consejo de Seguridad aprobó la resolución 1368, la cual reconoció precipitadamente el derecho a la autodefensa colectiva consignado en la Carta de las Naciones Unidas, acelerando así el comienzo del nuevo conflicto.

45 Según estimaciones oficiales, las víctimas llegaron a 3 mil 546 personas. Patterns of Global Terrorism 2001, Departamento de Estado, 21 de mayo de 2002.

46 Baltasar Rodríguez, Enrique, Afganistán y la geopolítica internacional, México, Plaza y Valdés, 2003, p. 124.

47 Ibidem, p. 125.

48 No era la primera vez que Afganistán sería atacada por culpa de O. Bin Laden, el 20 de agosto de 1998. Clinton declaró que Estados Unidos de América había lanzado un ataque con misiles crucero contra objetivos terroristas en Afganistán y Sudán. Bodansky, Yossef, Bin Laden, el hombre que declaró la guerra a Estados Unidos, Chile, Aguilar, 2001, p. 15. 
Allanado el camino, el 7 de octubre del 2001 Estados Unidos de América atacó militarmente a Afganistán, convirtiéndose dicho conflicto en el más disimétrico ${ }^{49}$ después de la Guerra de Vietnam. Así, la guerra contra el terrorismo del presidente Bush contempla dos dimensiones: el conflicto asimétrico (contra grupos terroristas) y el conflicto disimétrico (contra Estados promotores del terrorismo).

Sin embargo, todas las grandes evoluciones estratégicas que hoy son presentadas como consecuencias del 11-S, a excepción de Afganistán, ya estaban en práctica antes de esa fecha, de hecho sólo la campaña a Afganistán es una consecuencia directa y original del 11-S. ${ }^{50}$

Es más, la designación del "eje del mal" no hace más que racionalizar en términos de legítima defensa una política hostil definida mucho antes de la "guerra contra el terrorismo", no hace más que retomar una lista de los Estados bribones" redactada por la administración Clinton, precisamente por las mismas razones (exportación de terrorismo y programa de construcción de armas de de destrucción masiva). ${ }^{51}$

"De hecho, desde el punto de vista de los objetivos, el intento inicial de encontrar las bases terroristas [en Afganistán] se ha revelado como un pretexto para imponer al país un orden constitucional al gusto de la coalición" 52 invasora liderada por Estados Unidos de América.

\section{B. Consecuencias politicas de la doctrina preventiva $y$ el terrorismo}

Digamos que entre las consecuencias políticas de alcance global, la principal y la que más preocupa a la comunidad internacional es que la doctrina preventiva sirva como instrumento discrecional para resolver conflictos y modificar mapas políticos regionales de acuerdo con los intereses de la superpotencia dominante y de sus aliados. ${ }^{53}$

49 Nos referimos a los conflictos sin simetría, pero entre actores muy desiguales en términos cuantitativos, como entre una potencia y un país atrasado, mientras que el concepto asimétrico indica una diferencia cualitativa, como un conflicto entre un Estado y un grupo terrorista. Baltasar Rodríguez, op. cit., nota 44, p. 135.

50 Roy, Oliver, Las ilusiones del 11 de septiembre. El debate estratégico frente al terrorismo, Buenos Aires, Fondo de Cultura Económica, 2003, p. 17.

51 Idem.

52 Di Blase, Antonietta, "Guerra al terrorismo y guerra preventiva en el derecho internacional", en Bimbi, Linda (ed.), No en mi nombre. Guerra y derecho, Madrid, Trotta, 2003, p. 135.

53 Véase Reinares, "Epílogo", op. cit., nota 13, pp. 173 y ss. 
Así, tras una serie de intentos fallidos de encontrar consenso en el Consejo de Seguridad de la $\mathrm{ONU}^{54}$ (para intervenir militarmente en Irak), Estados Unidos de América atacó Irak, quebrantando así casi todos los principios básicos con los que se rige el derecho internacional contemporáneo.

Otra consecuencia es el lamentable aprovechamiento de la situación por parte de Israel, que cada vez que es víctima de un atentado terrorista, envía tropas "en represalia" a territorio bajo control de la autoridad palestina, con la excusa de actuar conforme al principio de autodefensa empleado por Estados Unidos de América en el conflicto con Afganistán.

Además, los acuerdos de Oslo fueron enterrados definitivamente por Israel ${ }^{55}$ retrazando la paz en Medio Oriente, a pesar de la Hoja de Ruta del 2002.

El apego a los grandes valores de la legalidad y la libertad individual se han debilitado y pasando a un segundo plano, desplazados por el obsesionante anhelo de seguridad. ${ }^{56}$

Esto se puede comprobar con sólo leer el Informe 2004 de Amnistía Internacional que concluye que siguieron infringiéndose normas internacionales en materia de derechos humanos en nombre de la "guerra contra el terror", lo que repercutió en millares de mujeres y hombres, quienes sufrieron detención ilegítima, juicios injustos y tortura, a menudo sin más motivo que su origen étnico o credo religioso.

\section{Medios jurídicos y políticos de lucha contra el terrorismo global}

La derrota del terrorismo global es una utopía sin la voluntad política y jurídica de los Estados. En este punto vamos a tratar de plantear soluciones políticas y jurídicas para confrontarlas con la realidad.

54 Se debe recordar que desde noviembre del 2002 una misión de observadores de la ONU ya venía trabajando en la búsqueda de armas de destrucción masiva en Irak. Además, en febrero del 2003 también se puso a descubierto (poco antes del ultimátum estadounidense) que las pruebas presentadas por Estados Unidos de América para justificar una intervención en Irak no eran contundentes.

55 Jiménez Bacca, Benedicto, El terrorismo internacional: una guerra sin tiempo y espacio, Lima, 2002, p. 20.

56 Idem. 
Desarrollar directrices de una estrategia de combate al terrorismo sería muy ambicioso en este trabajo, sin embargo podría enumerar algunas alternativas a tomar en cuenta.

Así, la estrategia antiterrorista debería basarse en la terminación a corto plazo de la violencia en Medio Oriente; una reconciliación entre el mundo islámico y el occidental, que reste apoyos al fundamentalismo violento; así como el fortalecimiento y la ampliación de los mecanismos legítimos de lucha contra el terrorismo global que dispone la comunidad internacional. 57

No se puede atacar la barbarie con más barbarie, no podemos aceptar la doctrina de la "legítima defensa preventiva" como medio de lucha contra el terrorismo. Más aún, no se puede aceptar como costumbre internacional dicha doctrina. Es más, en un reciente informe del Instituto de Estudios Estratégicos de Londres se afirmó que la guerra en Irak fortaleció a la red terrorista Al Qaeda.

Para que se configure un cambio en la costumbre internacional a favor de la legítima defensa preventiva, en caso de posibles ataques terroristas, es necesario remitirse primero a las normas generales del derecho internacional y a la práctica o la toma de posición de los Estados (opinio iuris) frente a ciertos hechos, pero también se debe tomar en cuenta el elemento subjetivo o psicológico que es la convicción de que lo que se está modificando es acorde con el derecho internacional.

Además, se deben tener en cuenta los precedentes relativos a las intervenciones armadas contra el terrorismo y las reacciones de los órganos de las Naciones Unidas así como de los otros miembros de la comunidad internacional tras el atentado del 11-S, ya sea en relación con la crisis afgana o con la situación en Irak. ${ }^{58}$

El secretario general de las Naciones Unidas ha ratificado que una aproximación multilateral y global en el marco de las Naciones Unidas constituye una garantía de eficacia de la lucha contra el terrorismo internacional en todos sus aspectos. ${ }^{59}$

57 Cfr. Olguín Uribe, Francisco, "La lucha contra el terrorismo. Un enfoque humanista", en Olloqui, José Juan de (coord.), Problemas jurídicos y políticos del terrorismo, México, UNAM, Instituto de Investigaciones Jurídicas, 2003, p. 229.

58 Di Blase, Antonieta, "Guerra al terrorismo y guerra preventiva en el derecho internacional", en Bimbi, Linda (ed.), No en mi nombre. Guerra y derecho, Madrid, Trotta, 2003, p. 126.

59 Ibidem, p. 145. 
Algunos autores señalan otras formas de combatir el terrorismo global del tipo de Al Qaeda. Así, afirma Castells, ${ }^{60}$ se requiere tres estrategias simultáneas y combinadas: destruir las redes terroristas operativas; impedir su reconfiguración, mediante la desarticulación de la infraestructura de recursos y comunicaciones en las que se basan; y prevenir la reproducción de esas redes actuando sobre las fuentes sociales de donde surgen. Cualquier intento de actuar en una dimensión sin hacerlo en las otras está condenado al fracaso a medio plazo.

Hay que reconocer los esfuerzos que en todos los ámbitos se han desplegado a partir del 11-S en la lucha contra el terrorismo.

Así, en el seno de las Naciones Unidas, el Consejo de Seguridad aprobó la Resolución 1373 (2001) en donde estipula una serie de medidas de obligatorias para todos los Estados, así como la creación del Comité contra el Terrorismo del Consejo de Seguridad.

También la Alianza Atlántica intervino activando por primera vez el artículo $\mathrm{V}$ del Tratado de Washington, en virtud del cual un ataque armado contra uno de sus aliados será considerado un ataque contra todos. ${ }^{61}$

Entre tanto, la Unión Europea consideró que el ataque a los Estados Unidos de América estaba dirigido contra los principios en los que se basa la construcción europea; por ello, preparó un plan de acción antiterrorista. ${ }^{62}$

\section{CONCLUSIONES}

1. Los sucesos del fatídico 11-S fueron calificados por el Consejo de Seguridad como actos terroristas y por el presidente de Estados Unidos de América como actos de guerra. Terrorismo y guerra se mezclarían según la percepción estadounidense.

2. La "guerra contra el terrorismo" se configuró en palabras del presidente W. Bush en dos ideas claves: los ataques terroristas como actos de guerra, que otorgaban a Estados Unidos de América el legítimo derecho de la autodefensa, y; catalogar como enemigos a los países que supuestamente apoyan a las organizaciones terroristas. La primera idea

60 Castells, op. cit., nota 12.

61 Independientemente de otras interpretaciones, lo cierto es que los países miembros del tratado ofrecieron todo su apoyo a los Estados Unidos de América.

62 Perpiñá Robert, Fernando, "El mundo tras el 11 de septiembre", en Olloqui, José Juan de (coord.), Problemas jurídicos y políticos del terrorismo, México, UNAM, 2003, p. 349. 
rompe la tradicional idea de guerra, como conflicto bélico entre Estados, y define un nuevo tipo de conflicto asimétrico entre la potencia más poderosa a nivel mundial y un enemigo casi virtual, con una estructura transnacional descentralizada, insertada dentro del horizonte de la globalización; empero, combatir la barbarie con más barbarie es contraproducente, no podemos aceptar la doctrina de la "legítima defensa preventiva" como medio de lucha contra el terrorismo. Más aún, no se puede aceptar como costumbre internacional dicha doctrina.

3. El 'terrorismo internacional privatizado' se ha tornado en terrorismo global y tiene entre sus indicadores más asombrosos al megaterrorismo, tal y como se manifestó aquel 11 de septiembre del 2001.

4. El terrorismo global, por su alcance mundial, es aquel que pone en peligro la paz y seguridad internacionales. A pesar de los 12 convenios existentes en materia de lucha contra el terrorismo, su enfrentamiento debe basarse en la cooperación de la comunidad internacional en su conjunto y en el cumplimiento fiel de las normas del ius cogens internacional en el marco de las Naciones Unidas, de ahí que los Estados deben adecuar su legislación interna para llenar ciertos vacíos legales que impidan dicho enfrentamiento.

5. El terrorismo global aprovecha los beneficios de la globalización como la Internet, que se ha convertido en el medio que facilita tareas fundamentales como las de proselitismo y reclutamiento, o incluso la gestión de recursos financieros.

6. La doctrina preventiva de Bush no es un diseño novedoso que nace como consecuencia de los ataques del 11 de septiembre, en realidad ha sido diseñada por un grupo de la élite neoconservadora estadounidense en sendos documentos que son publicados en la página Web del Project for the New American Century.

7. A raíz de los atentados del 11 de septiembre del 2001, la agenda internacional del desarrollo ha sido desplazada por la agenda de la seguridad. Actualmente, el apego a los grandes valores de la legalidad y la libertad individual se han debilitado y han pasado a un segundo plano, desplazados por el obsesionante anhelo de seguridad, lo que es conocido como "securitización" de la agenda internacional. Por lo que preocupa que la doctrina preventiva sirva como instrumento discrecional para resolver conflictos de acuerdo con los intereses de la superpotencia dominante y de sus aliados. 